\title{
Monitoring the Health Conditions of Miners at High Altitude Using Internet of Things Technology
}

\author{
N.Swarupa Kumari ${ }^{1}$, Vamshi Krishna Sabbi ${ }^{2}$, Abhishek Kumar Tripathi ${ }^{3}$, \\ Department of Electronics and Communication ${ }^{1,2}$, \\ Godavari Institute of Engineering and Technology,Rjy ${ }^{1,2}$ \\ Department of Mining Engineering ${ }^{3}$, \\ Godavari Institute of Engineering and Technology, Rjy ${ }^{3}$ \\ Email: swarupa.3366@gmail.com ${ }^{1}$, vamshi@giet.ac.in ${ }^{2}$, abhi12@giet.ac.in $^{3}$
}

\begin{abstract}
Miners working at high elevation must deal with varying climatic condition and physiological challenges without specific therapeutic supervision. Many mines in India are situated at a high elevation which forces the miners to work under such hazardous zone. Thus, the mining companies always searching for a proper framework which gives adequate information of miner's health at mining environmental condition. The security and wellbeing programs should always keep in mind on designing any framework. The aim of this paper is to design a prototype health monitoring gadget which can measure the heartbeat of the miner at different level of altitude while digging. This paper also demonstrates the variation of oxygen concentration and atmospheric pressure with the altitudes. The various sensors of the proposed framework are used in the prototype which will be installed on the wearing jackets of miners to accomplish a useful gadget and most extreme solace for the clients. The used noninvasive sensors will propagate all the collected information to the centralized station through Internet of Things (IOT) technology.
\end{abstract}

Index Terms- Physiological challenges, Internet of Things (IoT), Ecological factors, Noninvasive sensors.

\section{INTRODUCTION}

Mining incorporates the extraction of any noninexhaustible assets, such as coal, oil, petroleum, gas etc. As such, mining is the activity of detaching minerals or land materials from the earth, which is covered by the earth surface, under a very harsh environmental condition. Therefore, mining activities put a negative impact on the public perception and minor's wellbeing.

Mining strategies can be grouped into two: surface mining and sub-surface mining [1]. Surface mining is the way toward expelling surface vegetation and debased issue. Surface mining, contains open-pit mining, quarrying, strip mining, evacuation of peak and landfill. Surface mining is a most often utilized technique. Affirmation of mines with great practices jumps out at the Worldwide Association for Institutionalization (ISO). ISO 9000 approved an "auditable natural administration framework" [2]. Likewise, confirmation is accessible through caring worldwide detailing activity.

An excavator is a man that excavates minerals like metal, coal and so on from the earth through mining methodology. Mining is a bigger debilitating task, causes bunches of medical issues [3] [4]. Asthma is a major disease, which any mining workers face during the course of the mining operation and the reason of its existence is supported by mining operations. In underground mining operation, a portion of the gases such as methane, acetylene, phosgene, carbon dioxide, carbon monoxide etc., causes malignancy or destructive consequences for miners. Also, mining likewise envelops skin haphazardness [5]. Further, the variation in temperature and dampness under mining environment is perilous to the labourer's wellbeing. It will cause physical sickness. There are numerous advances made to improve the life of miners in mining environment specialists at high elevation. In the same series the Internet of things (IOT) technology can play a vital role to improve the life of miners (specially, those are working at high elevation).

Most ideal approach to improve the miner's life is by observing of laborers' wellbeing [6]. This paper demonstrates another framework to support the strength of miners and furthermore screen the variations in the environment. In this way, the enhancement of miner's life specialist's wellbeing and guarantees a happy with workplace. For this reason, the framework comprises of an assortment of sensors, microcontroller, voice ready framework and a checking framework [7].

\section{USAGE OF IOT IN MONITORING THE HEALTH CONDITIONS}


As of now, there are a few frameworks used to screen the strength of miners. The history is beginning with Igo B. Shirkov, who suggest a framework called, "microwave autodyne sensor for observing of heart musicality of excavators" [9]. In his work, a sensor is utilized to ascertain the cardiovascular beat of excavators. The usage of sensor is to receive a shot by taking Doppler Impact guideline into the consideration. The key component used in his work was microwave sensor, which was used for looking through the general population present under the mine and discover heart rate of miners. Further, Valdo Henriques and Reza Malekian designed another framework in 2016 which was termed as "Mine wellbeing framework utilizing remote sensor arrange" [8]. One more framework created by Ishan Tripathi, in which remote condition and voice ready parameters were considered in designing the framework [7] [10].

\section{EXPERIMENTAL SET-UP AND DATA ACQUISITION}

Figure 1 represents the entire experimental set-up of the present research work. In this, collection and checking of the physiological nature of the miners are recording and monitoring in real time. The collected parameters, which are collected by the purposed sensor, are transmitted to the centralized observing framework through on board Wi-Fi. Further, the data will be visualized and recorded at centralizing station which can be monitored by supervisor through a graphical user interface (UI). This information can be utilized as a part of the supervising stage to take proper action against any abnormal condition. The parameters which can be recorded by the purposed experimental setup are such as heart rate (HR), respiration rate (RR), ambient temperature (AT), pulse

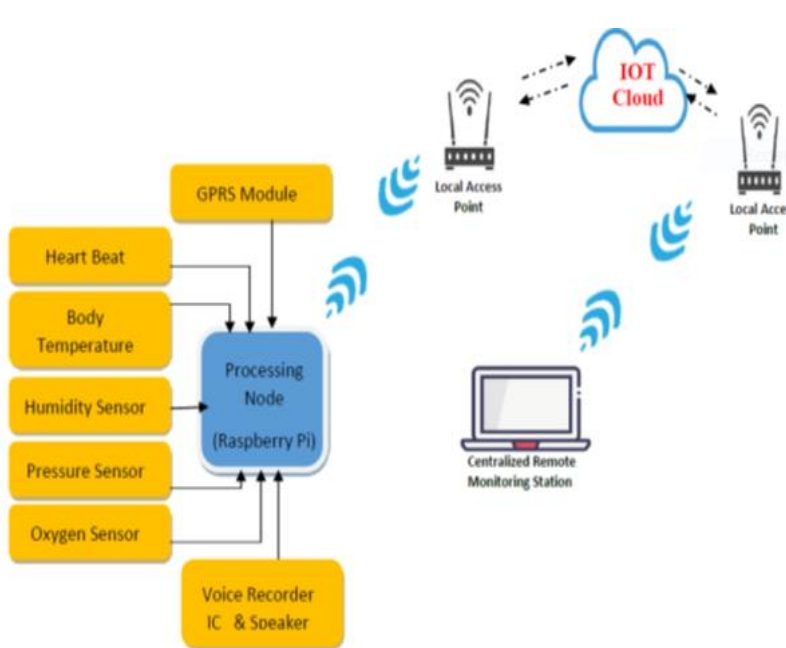

Figure.1 Framework of the proposed model

range (PR), atmospheric pressure (AP), oxygen level (OL) and relative humidity $(\mathrm{RH})$. In this paper, the
HR, OL and AP were observed at different level of altitude. The hardware implementation of the experimental set-up is as shown in Figure 2. The detailed description of components used in experimental setup is discussed in the Table 1.

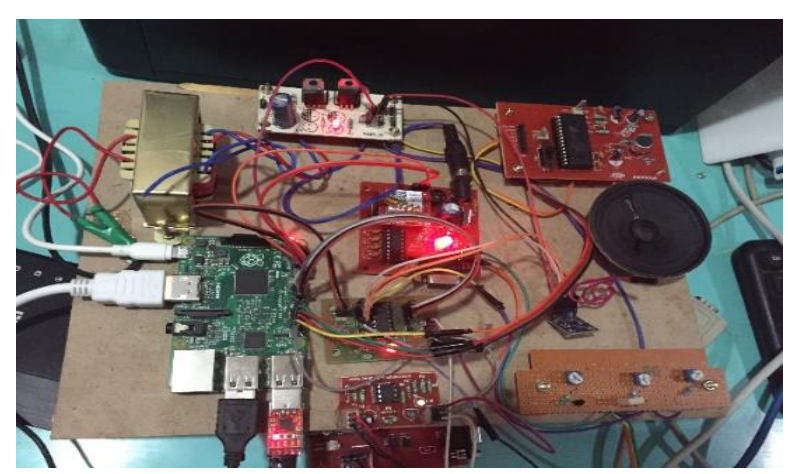

Figure 2. Hardware of experimental set-up

For the measurement of heartbeat by the purposed setup the different age group of miners were selected. In which, there ages vary from 25 years to 55 years. Thereafter, the heartbeat of each miners was recorded at three different level of altitude such as ground level, 100 feet 200 feet. Correspondingly, the oxygen concentration and atmospheric pressure were recorded with different level of altitude. Afterward, the percentage reduction of oxygen level at various altitude were calculated with reference to the ground level.

Table 1. Components used in experimental setup

\begin{tabular}{|c|c|c|}
\hline Sl.No. & Components & Purpose \\
\hline 1 & $\begin{array}{l}\text { Raspberry Pi } 3 \\
\mathrm{~B}+\end{array}$ & $\begin{array}{l}\text { To collect and process the } \\
\text { data based on applied } \\
\text { algorithm }\end{array}$ \\
\hline 2 & PC Monitor & $\begin{array}{l}\text { To display the status of } \\
\text { data }\end{array}$ \\
\hline 3 & Temperature & To sense the body and the \\
\hline 4 & Oxygen sensor & $\begin{array}{l}\text { To detect the mine gases } \\
\text { (such as methane, oxygen, } \\
\text { carbon oxide and carbon } \\
\text { monoxide) }\end{array}$ \\
\hline 5 & DHT sensor & To sense the humidity and \\
\hline 6 & GPRS & $\begin{array}{l}\text { To locate the position of } \\
\text { the miners }\end{array}$ \\
\hline 7 & $\begin{array}{l}\text { Pressure } \\
\text { sensor }\end{array}$ & $\begin{array}{l}\text { To measure atmospheric } \\
\text { pressure at altitude. }\end{array}$ \\
\hline 8 & $\mathrm{WiFi}$ & $\begin{array}{l}\text { To provide the wireless } \\
\text { transmission medium }\end{array}$ \\
\hline 9 & Voice IC & $\begin{array}{l}\text { To record the voice of } \\
\text { miners }\end{array}$ \\
\hline 10 & Pulse sensor & $\begin{array}{l}\text { To record the miners pulse } \\
\text { rate }\end{array}$ \\
\hline
\end{tabular}




\section{Available online at www.ijrat.org}

\section{RESULTS AND DISCUSSION}

The behaviour of heart rate of miner of different age group ranging from 25 years to 55 years were recorded at three different altitude (namely, ground level, 100 feet and 200feet) and presented in Figure 3. It was observed that heartbeat of the miner increases with their age at all level of altitude. Figure 3 depicts that the heartbeat of the miner increases with the altitude which may touch the abnormal limit of heartbeat of any miner. Therefore, under such mining environment the purposed framework will be useful for taking the proper preventive measures during the course of any abnormal condition which may occur with any miner.

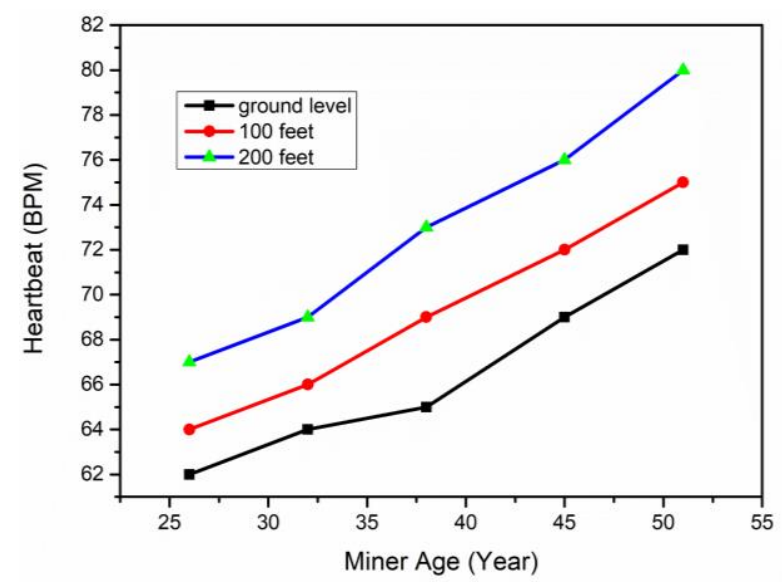

Figure.3. Heart beat range of miner working at various altitude

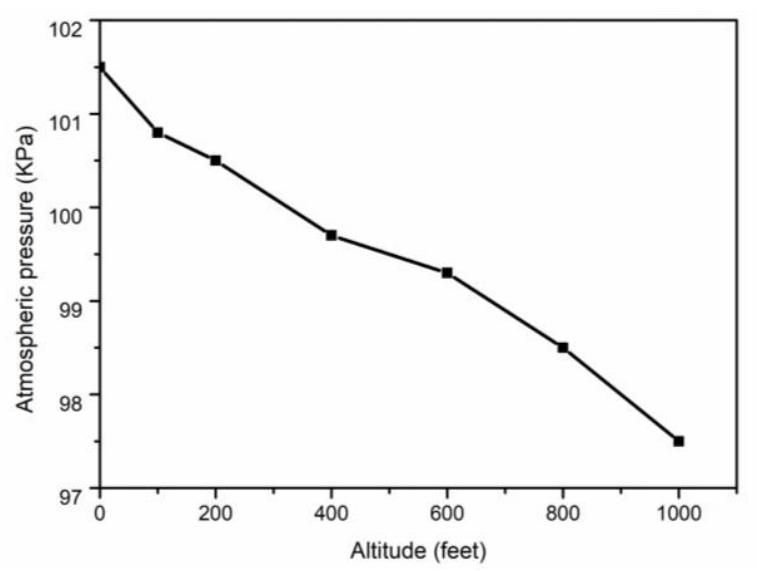

Figure.4. Percentage reduction in oxygen level with altitude

The percentage reduction of oxygen concentration with altitude were recorded and presented in the Figure 4 which shows that the percentage reduction of oxygen concentration increases with increases in height. It is well proven fact that sufficient amount of oxygen is required for a healthy working condition. The reduction in oxygen concentration degrades the quality of work by affecting the miner's health. The working performance of the miner is affected by the altitude. The miners working efficiency is directly depends on the oxygen consumption, which decreases at high altitude due to less oxygen in a given volume of air. Moreover, the atmospheric pressure with altitude is presented in Figure 5 which shows the reduction of atmospheric pressure with altitude. The

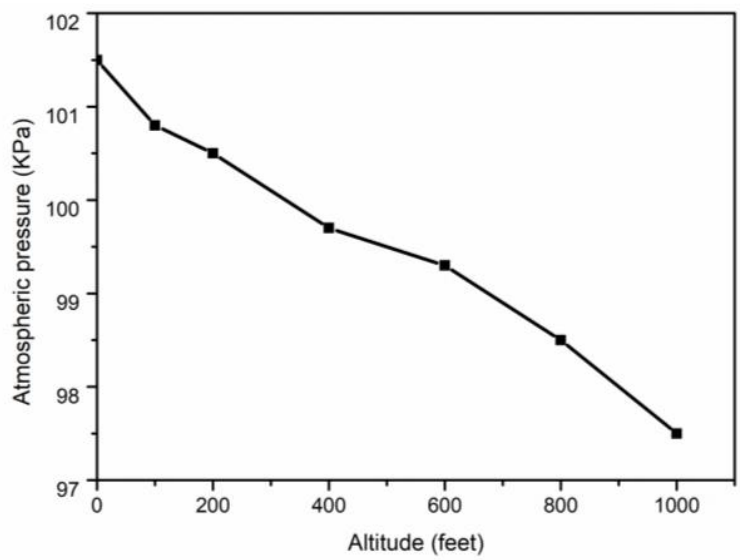

reduction of atmospheric pressure reduces the inhaling of oxygen by miners which can degrades the health of the miners.

Figure.5. Variation of atmospheric pressure with altitude

\section{CONCLUSIONS}

The wellbeing of a miners is very critical when they are working at high altitude. At high altitude they undergo from various physical and psychosocial changes. In this paper an attempt has been made to investigate the few operating parameters of miners such as heart rate, oxygen level and atmospheric pressure with the variations in the altitude of the workplace. In this paper, the increase in heartbeat was reported with the altitude and age. Further, the decrease in oxygen concentration and atmospheric pressure was recorded with respect to increase in altitude. This may degrade the working efficiency of the miners at the workplace which is located at the various altitude. This study will help to draw a suitable framework for the miners those are working at the high level of workplace in such a manner that a prior preventive measure can be taken to avoid any hazards which is associate with any abnormal condition.

\section{REFERENCES}

[1]. M. T. Lazarescu, Plan of a WSN stage for long haul natural checking for IoT applications, IEEE J. Emerg. Sel. Points Circuits Syst., vol. 3, no. 1, pp. 4554, Blemish. 2013.

[2]. Kondamudi Siva Sai Smash, A.N.P.S.Gupta, IoT based Information Lumberjack Framework for 
climate checking utilizing Remote sensor systems, vol 32 no. 2 ,Feb 2016.

[3]. Siyuan Chen, Yu Wang, Limit of Information Accumulation in Discretionary Remote Sensor Systems, IEEE Trans. Parallel Tirade. Syst., vol. 23, no. 1, pp. 5260, Jan. 2012.

[4]. K.Romer and F. Matter, \|The configuration space of remote sensor networks, \|IEEE Remote Commun., vol.11, no.6, pp.54-61, Dec.2004.

[5]. A. Hasler, I. Talzi, C. Tschudin, and S. Gruber, -Wireless sensor arranges in permafrost ask about - Thought, necessities, execution and challenges, $\|$ in Proc.

[6]. B. Siliverstovs D. Herzer "Manufacturing exports mining exports and growth: conintegration and causality analysis for Chile (1960 - 2001)" Applied Economics pp. 153-167 2007.

[7]. . "Annual Report of Chilean Mining 2014" National Service of Geology and mining Chile 2014.

[8]. D. Jimenez "High altitude intermittent chronic exposure: Andean miners" Hypoxia and the Brain pp. 284-91 1995.

[9]. H.- Y. Chiu "Early morning awakening and nonrestorative sleep are associated with increased minor non-fatal accidents during work and leisure time" Accid. Anal. Prev. vol. 71C pp. 10-14 2014.

[10]. S. C. Panchal, Universal Diary of Unadulterated and Connected Exploration in Designing and Innovation, Vol: 844- 848., May.2015.

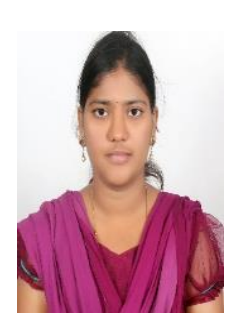

\section{N.Swarupa Kumari}

She is pursuing her M.Tech in ECE Department with specilization in VLSI Design at Godavari Institute of Engineering and Technology, Rajahmundry. She has carried out her project work at Centre of Internet of Things.

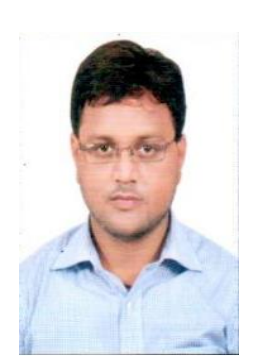

\section{Vamshi Krishna Sabbi}

Vamshi Krishna Sabbi received his B.Tech Degree in E\&T Engineering from ITM Gwalior, RGPV, Bhopal and M.Tech degree in VLSI Design in 2008 from C-DAC, Noida, GGSIP University Delhi. is pursuing his Ph.D in Supercomputing. Currently he is working as Associate Professor in ECE Department at Godavari Institute of Engineering and Technology. He is campus incharge for Centre of Internet of Things development at GIET Campus.

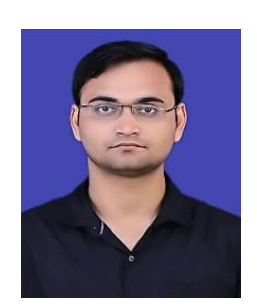

\section{Dr.Abhisek Tiripathi}

Abhishek Kumar Tripathi received his B. Tech degree in Electrical Engineering from BIT Durg in 2012 and $M$. Tech degree in Mining Engineering in 2014 from National Institute of Technology Rourkela, India. He worked for his Ph.D. degree in National Institute of Technology Karnataka, Suarthkal from 2015-2018 in Mining Engineering Department. He is also a member of several professional bodies. He awarded as a Best Research Paper Award in 2 nd International Conference on Paradigm in Engineering \&amp; Technology (ICPET-2018) during 28 th and 29 th December 2018. He recognized and honored as a Fellow of Engineering Research Council (FERC) by Global Journals, a society Accredited ISO Certified and United State Corporation Under Open Association of Research Society (USA). Currently, he is working as an Assistant Professor in Godavari Institute of Engineering and Technology (Autonomous), Rajahmundry, Andhra Pradesh, India. 